\title{
Guanine Nucleotide-Binding Protein G(o) Subunit Alpha
}

National Cancer Institute

\section{Source}

National Cancer Institute. Guanine Nucleotide-Binding Protein G(o) Subunit Alpha. NCI

Thesaurus. Code C114350.

Guanine nucleotide-binding protein $\mathrm{G}(\mathrm{o}$ ) subunit alpha (354 aa, $\sim 40 \mathrm{kDa}$ ) is encoded by the human GNAO1 gene. This protein is involved in the regulation of $\mathrm{G}$ protein signaling. 